\title{
A Clinical Experience on Sulodexide in the Treatment of Patients with Diabetic Nephropathy
}

Sabeur Dakhli ${ }^{1 *}$, Adel Khedher ${ }^{2}$, Zidi Borni ${ }^{3}$, Abdellatif Achour ${ }^{4}$ and Jamil Hachicha ${ }^{5}$

${ }^{1}$ Centre Medical El Farabi, Ariana, Tunisia

${ }^{2}$ Internal Medicine Service M8, Hospital Charles Nicolle, Tunis, Tunisia

${ }^{3}$ Department of Endocrinology Military Hospital, Tunis, Tunisia

${ }^{4}$ Nephrology Service, Hospital Sahloul, Sousse, Tunisia

${ }^{5}$ Nephrology Service, Hospital Hedi Chaker, Sfax, Tunisia

"Corresponding author: Sabeur Dakhli, Centre Medical El Farabi, Menzah 6, Ariana 2091, Tunisia, Tel: 0021671230220; E-mail: saberdakhli@yahoo.fr

Received date: November 25, 2016; Accepted date: December 19, 2016; Published date: December 27, 2016

Copyright: $\odot 2016$ Dakhli S, et al. This is an open-access article distributed under the terms of the Creative Commons Attribution License; which permits unrestricted use; distribution; and reproduction in any medium; provided the original author and source are credited.

\begin{abstract}
Background: Diabetic nephropathy, characterized by albuminuria, is a severe complication of diabetes mellitus, leading cause of end-stage renal disease. The aim of the present study was to evaluate the efficacy and safety of sulodexide, alone or in combination with captopril, versus captopril alone in consecutive adult patients with diabetic nephropathy.
\end{abstract}

Methods: Patients aged $\geq 18$ years, with type 1 or type 2 diabetes mellitus and albumin excretion rate (AER) $\geq$ $30 \mathrm{mg} / 24 \mathrm{~h}$, without severe renal insufficiency, cardiac or hepatic insufficiency, or haematuria, were enrolled. Patients were treated with captopril $25 \mathrm{mg}$ twice daily, sulodexide $25 \mathrm{mg}$ twice daily, or a combination of captopril 25 $\mathrm{mg}$ twice daily + sulodexide $25 \mathrm{mg}$ twice daily for 6 months. The primary endpoint was the evaluation of AER. Secondary endpoints included evaluation of arterial blood pressure, fasting glucose, $\mathrm{HbA} 1 \mathrm{c}$, serum creatinine and uricemia and safety.

Results: Globally, 123 patients were enrolled and treated with captopril alone $(n=42)$, sulodexide alone $(n=53)$ or sulodexide plus captopril $(n=28)$. After adjustment for initial albuminuria, the AER reduction at T3 and T6 versus T0, although highly significant in all treatment groups, was higher in patients treated with the combination or with sulodexide alone than in patients given captopril alone (further decrease of $17.6 \%$ and $18.2 \%$ at T3 and of $29.3 \%$ and $19.8 \%$ at $T 6$, respectively). In the whole population, serum creatinine and uric acid levels increased during the study, $\mathrm{HbA} 1 \mathrm{c}$ and fasting glucose levels increased from T0 to T3 and remained stable thereafter, while blood pressure was constant throughout the study. Sulodexide was well tolerated.

Conclusions: Long term administration of sulodexide $50 \mathrm{mg} /$ day, both in monotherapy or in combination with captopril, is effective and well tolerated in reducing proteinuria in diabetic patients and can be considered a valid therapeutical option in order to prevent major complications and reduce morbidity and mortality in this population.

Keywords: Sulodexide; Diabetic nephropathy; Macroalbuminuria; Microalbuminuria; Captopril

\section{Introduction}

Diabetes mellitus (DM) is characterised by specific changes in microvessels, thus causing diabetic microangiopathy, namely nephropathy and retinopathy, and macroangiopathy (including neuropathy) [1]. Diabetic nephropathy is a chronic and severe complication of, more frequent in type 1 (up to $40 \%$ of cases) than in type 2 (approximately $20 \%$ of cases). This complication is a leading cause of end-stage renal disease and has a significant impact on morbidity and mortality and on healthcare costs $[2,3]$.

Diabetic nephropathy is initially characterized by microalbuminuria (defined as an albumin excretion rate (AER) of 30-299 mg / 24 hours or albumin/creatinine ratio (ACR) between 30 and $299 \mu \mathrm{g}$ albumin / $\mathrm{mg}$ creatinine), with subsequent later progression to macroalbuminuria (defined as an AER $\geq 300 \mathrm{mg} / 24$ hours or ACR $\geq$
$300 \mu \mathrm{g}$ albumin / mg creatinine) [2,4,5]. Without specific intervention, $20-40 \%$ of diabetic patients with microalbuminuria will progress to overt nephropathy with macroalbuminuria and, within 20 years, $20 \%$ of patients will develop end-stage renal disease. Albuminuria correlates both with risk of renal failure and cardiovascular events and mortality [1]. For these reasons, microalbuminuria and macroalbuminuria are not only good predictors of the progression of diabetic nephropathy to end-stage renal disease, but are also considered a target for treatment of the renal disease and an indicator of a drug's efficacy in preventing or delaying the onset of end-stage renal failure in diabetic patients [5].

The goal of treatment is to prevent the progression from micro- to macroalbuminuria, the decline of renal function in patients with macroalbuminuria and the occurrence of cardiovascular events with an early multi-pharmacological approach $[4,6]$. The main pathological features include desulfation and degradation of the glomerular matrix, thickening of the basal membrane and mesangial proliferation, and extra- and intracapillary hyalinosis [1,2]. Several mechanisms have been identified for explaining endothelial damage and proliferation. 
Page 2 of 9

Among them is the alteration of endothelial permeability due to the degradation and reduction of heparan-sulfate, a glycosaminoglycan component of the extracellular and basement membrane matrix. The decreased concentration of glycosaminoglycans causes a loss of negative-charged molecules from the glomerular basement membrane, a decreased activity of the anionic filtration barrier that prevents the passage of proteins from blood to urine, a greater synthesis of type II collagen and the activation of growth factors such as TGF-beta [1-3]. Glycosaminoglycans strongly influence thickness, integrity and permselectivity of the endothelial glycocalyx: the effect of exogenous administration of glycosaminoglycans on the sulfation and synthesis of proteoglycans and on the differential expression of type IV collagen concur in maintaining the normal structure and permeability of the glomerular basement membrane [2]. Other alternative hypotheses have been advocated to explain the favourable remodelling effect of glycosaminoglycans at renal level: downregulation of proteases, the inhibition of heparanase, the modulation of extracellular mesangial matrix synthesis, the inhibition of the TGF $\beta$-1 gene, the modulation of angiotensin II mediated cellular signalling, the restoration of glomerular basement membrane anionic charges, and the inhibition of macrophage infiltration and activation $[2,6]$.

Basically, endothelial dysfunction is the common starting point both for macro- and microangiopathy. The pattern of endothelial damage in diabetes is a complex phenomenon of abnormal augmentation of vascular permeability, gradual change of endothelial cells towards a secretory phenotype and enhanced cell proliferation [1]. The basis for the prevention of diabetic nephropathy is the treatment of its known risk factors (hypertension, hyperglycemia, smoking, and dyslipidemia) with an intensive blood glucose, blood pressure and lipid level control [4]. In this context, renin-angiotensin system blockade with angiotensin-converting enzyme inhibitors (ACE-I) or angiotensin receptor blockers (ARBs) confers an additional benefit on renal function. However, these strategies could not be effective in some patients with diabetes and novel and innovative therapeutic strategies are warranted.

Sulodexide (Vessel Due $\mathrm{F}^{\bullet}$ ) is a specific, highly purified mixture of glycosaminoglycans (a fast-moving heparin fraction with affinity for antithrombin III and a dermatan sulphate fraction with affinity for heparin cofactor II), with a very high tropism for vessel endothelium ( $90 \%$ of the product is found in the endothelium and its concentration is about 20-30 times higher than in other organs) [7-11]. Among its several well recognized activities on blood and vasculature (anticoagulant and venous/arterial anti-thrombotic, hemorrheologic, antiatherosclerotic, antilipidemic and antiproliferative effect), sulodexide is able to guarantee the vessel wall normal permeability, preventing the heparin sulphate degradation, maintaining or restoring the normal electronegativity of vessel walls and inhibiting extracellular matrix expansion between the vessel wall cells, and exibits an antiinflammatory activity $[8,9,12,13]$. Several experimental and human studies demonstrated the favourable anti-proteinuric effect of sulodexide therapy in diabetic patients with nephropathy [14-21].

The aim of the present study was to evaluate the efficacy and safety of sulodexide, alone or in combination with captopril, versus captopril alone in consecutive adult patients with diabetic nephropathy.

\section{Subjects and Methods}

\section{Study design}

This multicenter prospective open study was conducted in patients with diabetic nephropathy in 5 nephrology centers in Tunisia between October 2006 (first patient enrolled) and August 2008 (last patient completing the study). The study was in adherence with the Declaration of Helsinky.

The main inclusion criteria were: age $\geq 18$ years, diabetes mellitus either type 1 or type $2, A E R \geq 30 \mathrm{mg} / 24 \mathrm{~h}$. Exclusion criteria were: severe renal insufficiency (estimated creatinine clearance $<30 \mathrm{~mL} /$ min), cardiac or hepatic insufficiency, haematuria, known hypersensitivity to mucopolysaccharides, haematuria haematuria or lactation.

Patients were enrolled in three groups, according to the investigator's judgment: captopril $25 \mathrm{mg}$ twice daily, sulodexide (Vessel due $\mathrm{F}^{\oplus}$, Alfa Wassermann, Italy) $25 \mathrm{mg}$ (equivalent to 250 lipoprotein lipase releasing units) twice daily, or a combination of captopril $25 \mathrm{mg}$ twice daily + sulodexide $25 \mathrm{mg}$ twice daily. All the study drugs were administered for 6 months. Concomitant therapies, notably antidiabetic, antihypertensive, hypolipidemic and anticoagulant, were administered throughout the study as required and recorded in the case report form.

Patients were visited at baseline (T0) and after three (T3) and six (T6) months of treatment. Patient's history and demographic characteristics were recorded at T0. AER was evaluated through a single 24-hour urine collection at T0, T3 and T6; urine albumin was determined by turbidimetry. Arterial blood pressure, fasting glucose, glycosylated hemoglobin (HbAlc), serum creatinine and uricemia were also measured at three-month intervals. Patients were questioned for intercurring adverse events at post-baseline visits.

The primary endpoint of the study was the evaluation of AER. Secondary endpoints included evaluation of arterial blood pressure, fasting glucose, HbAlc, serum creatinine and uricemia as well as safety.

\section{Statistical analysis}

Quantitative data have been summarised using arithmetic means \pm standard deviation (SD) if normally distributed or geometric means if log-normally distributed. Categorical data have been reported as proportions of non-missing data.

Baseline albuminuria was classified as microalbuminuria (30-300 $\mathrm{mg} / 24 \mathrm{~h}$ ) or macroalbuminuria (>300-2000 mg/24 h). Creatinine clearance was estimated using the Cockroft-Gault formula and adjusted for body surface area by the equation of DuBois and DuBois. Baseline characteristics were compared by analysis of variance (ANOVA) if continuous and by the chi-square test if categorical. Correlations between continuous variables have been expressed using Pearson's $r$.

Laboratory data including AER and blood pressure were analysed by ANOVA or analysis of covariance (ANCOVA), both for repeated measures. Model-derived 95\% confidence intervals (95\% CI) have been reported for each visit and for changes from T0 to T3 and T6. Only patients having a measure at baseline and at least one after baseline (T3 or T6) were included in the main analysis of each variable. To allow inclusion of subjects with a missing observation at either T3 or T6, 
data were examined using repeated-measure mixed models with subjects as random effect; the structure of the covariance matrix was chosen according to the log-likelihood criterion $[22,23]$.

AER values were analysed after logarithmic transformation. Fixed effects in the main analysis were time of visit, treatment, baseline albuminuria (micro- or macro-), DM type and DM duration, as well as the interactions of visit with treatment and with baseline albuminuria. ANCOVA models were also examined considering for inclusion, as additional fixed effects, baseline creatinine clearance adjusted for body surface area, age, sex, weight, body mass index (BMI), concomitant diseases, smoking, dwelling area, and their interactions with visit and baseline albuminuria, provided that they significantly improved the model. Sensitivity analyses were conducted in patients with complete observations at all visits rather than adjusting for missing values at either T3 or T6. Alternative analyses were carried out with observations at T3 and T6 as the dependent variable and including the baseline numerical value among the covariates.

Serum creatinine, uricemia, $\mathrm{Hb} 1 \mathrm{Ac}$, fasting glucose and blood pressure were analysed using mixed ANOVA or ANCOVA models for repeated measures including time of visit, treatment and their interaction; patients' characteristics were considered as additional fixed effects if they significantly improved the model.

Body weight changes from T0 to T6 of at least $2 \mathrm{~kg}$ were analysed using Wilcoxon's signed rank test to detect an overall trend in either direction or Kruskal-Wallis test to detect an overall difference due to treatments.

Incidence rates were calculated for adverse events, and were compared between treatment groups using risk ratios (RRs) with $95 \%$ $\mathrm{CI}$ and chi-squared p-values based on the Mantel-Haenszel method. Multiple logistic regressions were used to test the association between patients' characteristics and the incidence of adverse events.

$\mathrm{P}<0.05$ has been considered as statistically significant. Sidak's correction was used when comparing treatments at each post-baseline visit (six comparisons); both uncorrected and Sidak-corrected p-values and CIs have been reported. Statistical analyses were carried out using the $\mathrm{SAS}^{\oplus}$ System version 8.2.

\section{Results}

\section{Patients}

Globally, 123 patients were enrolled and treated with captopril alone $(n=42,34 \%)$, sulodexide alone $(n=53,43 \%)$ or sulodexide plus captopril $(n=28,23 \%)$.

All patients were considered evaluable for safety as all had taken at least one dose of the study drugs and were visited at least once after T0. A patient treated with sulodexide alone was withdrawn because of nausea after 5 weeks. Another subject treated with sulodexide alone interrupted the study for unkwown reasons after T3.

The main demographic and clinical characteristics of the patients evaluated are reported in Table 1. Mean AER values were highest in the combination group and lowest in the sulodexide group (overall difference between treatments, $\mathrm{p}<0.0001$; all pairwise differences corrected for multiple comparisons, $\mathrm{p}<0.012$ ). The mean history of diabetes was shortest in the sulodexide group, while subjects with type 1 diabetes were preferably treated with the combination (overall difference, $\mathrm{p}=0.039$ ). Almost all patients had normal (estimated creatinine clearance $\geq 80 \mathrm{~mL} / \mathrm{min}$ ) or mildly impaired $(50-80 \mathrm{~mL} / \mathrm{min}$ ) renal function, with a similar distribution across treatment groups.

\begin{tabular}{|c|c|c|c|c|}
\hline & $\begin{array}{l}\text { All } \\
(123 \\
\text { patients) }\end{array}$ & $\begin{array}{l}\text { Captopril } \\
\text { (42 } \\
\text { patients) }\end{array}$ & $\begin{array}{l}\text { Sulodexi } \\
\text { de } \\
\text { (53 } \\
\text { patients) }\end{array}$ & $\begin{array}{l}\text { Combinat } \\
\text { ion } \\
\text { (28 } \\
\text { patients) }\end{array}$ \\
\hline \multicolumn{5}{|l|}{ Dwelling area, $\mathrm{N}(\%)$} \\
\hline$N$ & 2 & 1 & 0 & 1 \\
\hline urban & $91(75)$ & $28(68)$ & $42(79)$ & $21(78)$ \\
\hline rural & $30(25)$ & $13(32)$ & $11(21)$ & $6(22)$ \\
\hline \multicolumn{5}{|l|}{ Age (years) } \\
\hline $\min -\max$ & $21-74$ & $33-70$ & $26-74$ & $21-71$ \\
\hline mean \pm SD & $51.9 \pm 9.9$ & $52.5 \pm 9.1$ & $52.2 \pm 9.7$ & $\begin{array}{l}50.3 \quad \pm \\
11.4\end{array}$ \\
\hline \multicolumn{5}{|l|}{ Sex, N (\%) } \\
\hline NA & 2 & 0 & 1 & 1 \\
\hline female & $40(33)$ & $16(38)$ & $15(29)$ & $9(33)$ \\
\hline male & $81(67)$ & $26(62)$ & $37(71)$ & $18(67)$ \\
\hline \multicolumn{5}{|l|}{ Weight (kg) } \\
\hline $\min -\max$ & $50-102$ & $55-100$ & $50-102$ & $56-99$ \\
\hline mean \pm SD & $74.8 \pm 9.7$ & $\begin{array}{l}74.8 \\
10.3\end{array}$ & $74.5 \pm 9.4$ & $75.3 \pm 9.5$ \\
\hline \multicolumn{5}{|l|}{ BMI $\left(\mathrm{kg} / \mathrm{m}^{2}\right)$} \\
\hline $\min -\max$ & $17.3-37.2$ & $21.5-37.2$ & $17.3-34.5$ & $22.0-36.7$ \\
\hline mean \pm SD & $26.9 \pm 3.5$ & $27.2 \pm 3.6$ & $26.6 \pm 3.4$ & $27.0 \pm 3.4$ \\
\hline \multicolumn{5}{|c|}{ Type of diabetes, $\mathrm{N}(\%)$} \\
\hline NA & 1 & 0 & 1 & 0 \\
\hline 1 & $11(9)$ & $2(5)$ & $3(6)$ & $6(21)$ \\
\hline 2 & $111(91)$ & $40(95)$ & $49(94)$ & $22(79)$ \\
\hline \multicolumn{5}{|c|}{ Duration of diabetes (years) } \\
\hline $\min -\max$ & $0-26$ & $1-24$ & $0-24$ & $5-26$ \\
\hline mean \pm SD & $14.0 \pm 6.0$ & $14.8 \pm 5.1$ & $12.0 \pm 6.6$ & $16.4 \pm 5.1$ \\
\hline \multicolumn{5}{|c|}{$\begin{array}{l}\text { Creatinine clearance }\left(^{*}\right), \mathrm{N} \\
(\%)\end{array}$} \\
\hline NA & 4 & 0 & 4 & 0 \\
\hline$\geq 30$ to $50 \mathrm{~mL} / \mathrm{min}$ & $2(2)$ & $1(2)$ & $1(2)$ & 0 \\
\hline$\geq 50$ to $80 \mathrm{~mL} / \mathrm{min}$ & $60(50)$ & $20(48)$ & $24(49)$ & $16(57)$ \\
\hline$\geq 80 \mathrm{~mL} / \mathrm{min}$ & $57(48)$ & $21(50)$ & $24(49)$ & $12(43)$ \\
\hline \multicolumn{5}{|l|}{ AER, N (\%) } \\
\hline NA & 4 & 0 & 3 & 1 \\
\hline 30 to $300 \mathrm{mg} / 24 \mathrm{~h}$ & $76(64)$ & $26(62)$ & $41(82)$ & $9(33)$ \\
\hline
\end{tabular}


Citation: Dakhli S, Khedher A, Borni Z, Achour A, Hachicha J (2016) A Clinical Experience on Sulodexide in the Treatment of Patients with Diabetic Nephropathy. J Nephrol Ther 7: 284. doi:10.4172/2161-0959.1000284

Page 4 of 9

\begin{tabular}{|l|l|l|l|l|}
\hline$>300$ to $2000 \mathrm{mg} / 24 \mathrm{~h}$ & $43(36)$ & $16(38)$ & $9(18)$ & $18(67)$ \\
\hline AER $(\mathrm{mg} / 24 \mathrm{~h})$ & & & & \\
\hline min - max & $30-2000$ & $40-2000$ & $30-1250$ & $100-2000$ \\
\hline geometric mean & 295 & 320 & 173 & 702 \\
\hline
\end{tabular}

$\mathrm{NA}=$ not available; $\mathrm{SD}=$ standard deviation; $\mathrm{BMI}=$ body mass index; $\mathrm{AER}=$ albumin excretion rate. $\left({ }^{*}\right)$ estimated using the Cockroft-Gault formula and adjusted for body surface area

Table 1: Patients' characteristics at entry.

\begin{tabular}{|c|c|c|c|c|}
\hline & $\begin{array}{l}\text { All } \\
\text { (123 patients) }\end{array}$ & $\begin{array}{l}\text { Captopril } \\
\text { (42 patients) }\end{array}$ & $\begin{array}{l}\text { Sulodexide } \\
\text { (53 patients) }\end{array}$ & $\begin{array}{l}\text { Combination } \\
\text { (28 patients) }\end{array}$ \\
\hline \multicolumn{5}{|l|}{ Smoking, N (\%) } \\
\hline no & $74(62)$ & $25(60)$ & $34(68)$ & $15(54)$ \\
\hline yes & $46(38)$ & $17(40)$ & $16(32)$ & $13(46)$ \\
\hline NA & 3 & 0 & 3 & 0 \\
\hline \multicolumn{5}{|l|}{ Comorbidities, N (\%) } \\
\hline Previous cerebrovascular accident & $1(1)$ & $0(0)$ & $0(0)$ & $1(4)$ \\
\hline Peripheral vascular disease & $6(5)$ & $1(2)$ & $2(4)$ & $3(11)$ \\
\hline Coronary disease & $13(11)$ & $10(24)$ & $2(4)$ & $1(4)$ \\
\hline Diabetic retinopathy & $54(44)$ & $24(57)$ & $14(26)$ & $16(57)$ \\
\hline Diabetic neuropathy & $23(19)$ & $7(17)$ & $7(13)$ & $9(32)$ \\
\hline Arterial hypertension & $56(46)$ & $19(45)$ & $20(38)$ & $17(61)$ \\
\hline Dyslipidemia & $14(11)$ & $6(14)$ & $3(6)$ & $5(18)$ \\
\hline Other disease & $3(2)$ & $0(0)$ & $2(4)$ & $1(4)$ \\
\hline Any disease & $76(62)$ & $29(69)$ & $29(55)$ & $18(64)$ \\
\hline \multicolumn{5}{|l|}{ Concomitant treatments, $\mathrm{N}(\%)$} \\
\hline Insulin & $31(25)$ & $9(21)$ & $10(19)$ & $12(43)$ \\
\hline Oral antidiabetic agents & $96(78)$ & $33(79)$ & $46(87)$ & $17(61)$ \\
\hline Beta-blockers & $20(16)$ & $10(24)$ & $6(11)$ & $4(14)$ \\
\hline Calcium-channel inhibitors & $33(27)$ & $14(33)$ & $10(19)$ & $9(32)$ \\
\hline Diuretics & $6(5)$ & $2(5)$ & $2(4)$ & $2(7)$ \\
\hline Other antihypertensive agents & $2(2)$ & $0(0)$ & $1(2)$ & $1(4)$ \\
\hline Acetylsalicylic acid & $46(37)$ & $18(43)$ & $17(32)$ & $11(39)$ \\
\hline Statins & $6(5)$ & $3(7)$ & $2(4)$ & $1(4)$ \\
\hline Fibrates & $6(5)$ & $2(5)$ & $3(6)$ & $1(4)$ \\
\hline Other drugs & $6(5)$ & $2(5)$ & $3(6)$ & $1(4)$ \\
\hline Any treatment & $123(100)$ & $42(100)$ & $53(100)$ & $28(100)$ \\
\hline
\end{tabular}

Table 2: Smoking, comorbidities and concomitant treatments.

Log-transformed AER at baseline was correlated with body-surface adjusted creatinine clearance $(\mathrm{r}=-0.29, \mathrm{p}=0.0021)$, creatininemia $(\mathrm{r}=0.23, \mathrm{p}=0.012)$ and diastolic blood pressure $(\mathrm{r}=0.28, \mathrm{p}=0.0021)$, while there was no correlation $(\mathrm{p}>0.40)$ with systolic blood pressure, uricemia, HbAlc and fasting glycemia.

As shown in Table 2, the patients treated with sulodexide had fewest concomitant diseases (overall difference, $\mathrm{p}=0.0046$ ), and all patients received one or more concomitant treatment, mainly oral antidiabetic agents, acetylsalicylic acid, calcium-channel inhibitors, insulin and beta-blockers. 


\section{Albumin excretion rate}

Seven patients lacking valid baseline or at least one post-baseline AER measure were excluded from this analysis, six in the sulodexide group (one withdrawal for adverse event, one not reported, four laboratory or reporting error) and one in the combination group (laboratory or reporting error). Patients lacking only one post-baseline measure were included. AER values observed throughout the study are reported in Table 3. Compared to baseline, average values (as geometric means) of AER at T3 and T6 were progressively lower in all groups; the time trend was therefore highly significant $(\mathrm{p}=0.0001)$. This reduction, however, was greater in microalbuminuric than in macroalbuminuric patients, both for the whole sample and for each treatment group. This difference must be accounted for when comparing treatment groups, as initial AER was not balanced among them. Unadjusted analysis of AER would favour sulodexide, the preferred treatment for initial microalbuminuria, over captopril and especially over the combination which was used mostly for macroalbuminuria. Table 4 shows the results of the main analysis of
AER adjusted for initial albuminuria, and additionally for diabetes type and duration as they significantly improved the model. The AER reduction at T3 and T6 versus T0, although highly significant in all treatment groups, was greater in patients treated with the combination or with sulodexide alone than in patients given captopril alone, with a further decrease of $17.6 \%$ and $18.2 \%$ with the combination and of $29.3 \%$ and $19.8 \%$ with sulodexide respectively at T3 and T6. Although the AER relative reduction at T3 was similar with the combination and with sulodexide, the former did not achieve multiplicity-corrected statistical significance compared with captopril because of the smaller number of patients. At T6 the improvement with sulodexide versus captopril was similar to that observed at T3, but was no longer statistically significant (after correction for multiplicity) as the variability was greater. The AER relative reduction with the combination progressed further at T6 achieving multiplicity-corrected statistical significance versus captopril, while the comparison with sulodexide was not significant.

\begin{tabular}{|c|c|c|c|c|c|c|c|c|}
\hline \multirow[t]{2}{*}{ Treatment } & \multirow[t]{2}{*}{ Visit } & \multicolumn{3}{|c|}{ Overall } & \multicolumn{2}{|c|}{$\begin{array}{l}\text { Macroalbuminuria } \\
\text { at T0 }\end{array}$} & \multicolumn{2}{|c|}{$\begin{array}{l}\text { Microalbuminuria } \\
\text { at T0 }\end{array}$} \\
\hline & & $\mathrm{N}$ & $\mathrm{mg} / 24 \mathrm{~h}$ & $\%$ of T0 & $\mathrm{N}$ & $\%$ of T0 & $\mathrm{N}$ & $\%$ of T0 \\
\hline \multirow[t]{3}{*}{ All } & T0 & 116 & 297 & & 42 & & 74 & \\
\hline & T3 & 115 & 212 & $71(66,77)$ & 42 & $82(78,86)$ & 73 & $66(60,73)$ \\
\hline & T6 & 113 & 163 & $55(50,61)$ & 42 & $69(63,76)$ & 71 & $48(41,56)$ \\
\hline \multirow[t]{3}{*}{ Captopril } & T0 & 42 & 320 & & 16 & & 26 & \\
\hline & T3 & 42 & 261 & $81(72,92)$ & 16 & $92(86,99)$ & 26 & $76(64,89)$ \\
\hline & T6 & 42 & 211 & $66(56,78)$ & 16 & $84(72,96)$ & 26 & $57(44,73)$ \\
\hline \multirow[t]{3}{*}{ Sulodexide } & T0 & 47 & 170 & & 8 & & 39 & \\
\hline & T3 & 46 & 107 & $63(56,71)$ & 8 & $77(69,85)$ & 38 & $61(53,70)$ \\
\hline & T6 & 45 & 81 & $48(41,56)$ & 8 & $57(47,70)$ & 37 & $47(38,58)$ \\
\hline \multirow[t]{3}{*}{ Combination } & T0 & 27 & 702 & & 18 & & 9 & \\
\hline & T3 & 27 & 504 & $72(62,83)$ & 18 & $76(71,81)$ & 9 & $64(48,85)$ \\
\hline & T6 & 26 & 368 & $52(42,65)$ & 18 & $64(56,73)$ & 8 & $34(22,54)$ \\
\hline
\end{tabular}

Table 3: AER at baseline (T0), after 3 months (T3) and after 6 months (T6) of treatment overall and stratifying by baseline albuminuria. AER $(\mathrm{mg} / 24 \mathrm{~h})$ and percent entries are geometric means $(95 \% \mathrm{CI})$ estimated by repeated-measures mixed-effect ANOVA models on log-transformed data including visit $(\mathrm{p}<0.0001$ overall), treatment $(\mathrm{p}<0.0001$ overall $)$ and their interaction $(\mathrm{p}=0.028$ overall $)$ and adjusting for missing values at either T3 or T6.

\begin{tabular}{|l|l|l|l|}
\hline Treatment & Visit & $\%$ of T0 & P-value \\
\hline Captopril & T3 & $83.5(75.5,92.4)$ & 0.0005 \\
\hline & T6 & $69.0(59.3,80.2)$ & $<0.0001$ \\
\hline Sulodexide & T3 & $68.3(61.2,76.3)$ & $<0.0001$ \\
\hline & T6 & $55.3(46.9,65.3)$ & $<0.0001$ \\
\hline Combination & T3 & $68.8(60.5,78.2)$ & $<0.0001$ \\
\hline
\end{tabular}


Page 6 of 9

\begin{tabular}{|l|l|l|l|}
\hline & T6 & $48.8(40.1,59.3)$ & $<0.0001$ \\
\hline Combination / Captopril (*) & T3 & $82.4(69.8,97.2)(65.9,103.0)$ & $0.022(0.13)$ \\
\hline & T6 & $70.7(55.0,90.8)(50.4,99.1)$ & $0.0069(0.041)$ \\
\hline Combination / Sulodexide (*) & T3 & $100.7(84.5,120.0)(79.5,127.5)$ & $0.94(1.0)$ \\
\hline & T6 & $88.1(67.5,115.0)(61.6,126.1)$ & $0.35(0.92)$ \\
\hline Sulodexide / Captopril (*) & T3 & $81.8(70.8,94.5)(67.3,99.4)$ & $0.0067(0.040)$ \\
\hline & T6 & $80.2(64.6,99.6)(59.9,107.4)$ & $0.046(0.25)$ \\
\hline $\begin{array}{l}\text { Cl=confidence interval; ANCOVA= analysis of covariance; DM=diabetes mellitus; AER=albumin excretion rate. (*) p-values and Cls corrected for multiple comparisons } \\
\text { are in square brackets }\end{array}$
\end{tabular}

Table 4: AER after 3 months (T3) and after 6 months (T6) of treatment as ratios of baseline (T0). Percent entries are geometric means (95\% CI) estimated by a repeated-measures mixed-effect ANCOVA model on log-transformed data adjusting for missing values at either T3 or T6. Model included visit $(\mathrm{p}<0.0001)$, treatment $(\mathrm{p}=0.017)$, baseline albuminuria (micro- or macro-, $\mathrm{p}<0.0001)$, DM type ( $\mathrm{p}=0.0094)$, DM duration $(\mathrm{p}<0.0001)$, the interactions of treatment by visit $(\mathrm{p}=0.014)$ and baseline albuminuria by visit $(\mathrm{p}=0.0007)$.

Consistent results were observed in subsidiary analyses with other repeated-measures ANCOVA models introducing plausible alternatives to the main model, namely exluding patients with missing data, including other factors significantly and independently associated with AER, and considering baseline AER values as a covariate (data not shown).

\section{Hematological variables and vital signs}

Means and 95\% CI of other hematological variables and blood pressure during the study, adjusted according to best-fit repeatedmeasures ANCOVA models, are shown in Figure 1. Overall, serum creatinine and uric acid levels increased, $\mathrm{HbAlc}$ and fasting glucose levels increased from T0 to T3 and remained stable thereafter, while systolic and diastolic blood pressure was fairly constant throughout the study. The increase in serum creatinine from T0 to T6 was significantly higher with captopril than with sulodexide $(5.7 \mu \mathrm{mol} / \mathrm{L}$ and $0.6 \mu \mathrm{mol} / \mathrm{L}$ respectively, $\mathrm{p}=0.005$ uncorrected, $\mathrm{p}=0.030$ corrected for multiple comparisons). Other changes did not significantly differ across treatment groups after correction for multiplicity.

Eleven patients (four in the captopril group, four in the sulodexide group and three in the combination group) had a body weight decrease of 2-3 kg from T0 to T6 while two patients (one captopril alone and one captopril plus sulodexide) had a body weight increase of $2 \mathrm{~kg}$. The trend toward weight reduction was statistically significant $(\mathrm{p}=0.007)$ with no difference due to treatments $(\mathrm{p}=0.76)$.

\section{Safety}

Twenty-three patients experienced one or more adverse events, mostly gastrointestinal (Table 5). The incidence of any adverse event was highest in patients treated with the combination and lowest in patients treated with sulodexide alone; the RR between these two groups was statistically significant $(\mathrm{p}=0.011)$ even after correction for multiple comparisons. No significant correlation was found between patients' characteristics and the incidence of adverse events. A patient interrupted the study because of nausea after 5 weeks of treatment with sulodexide alone.

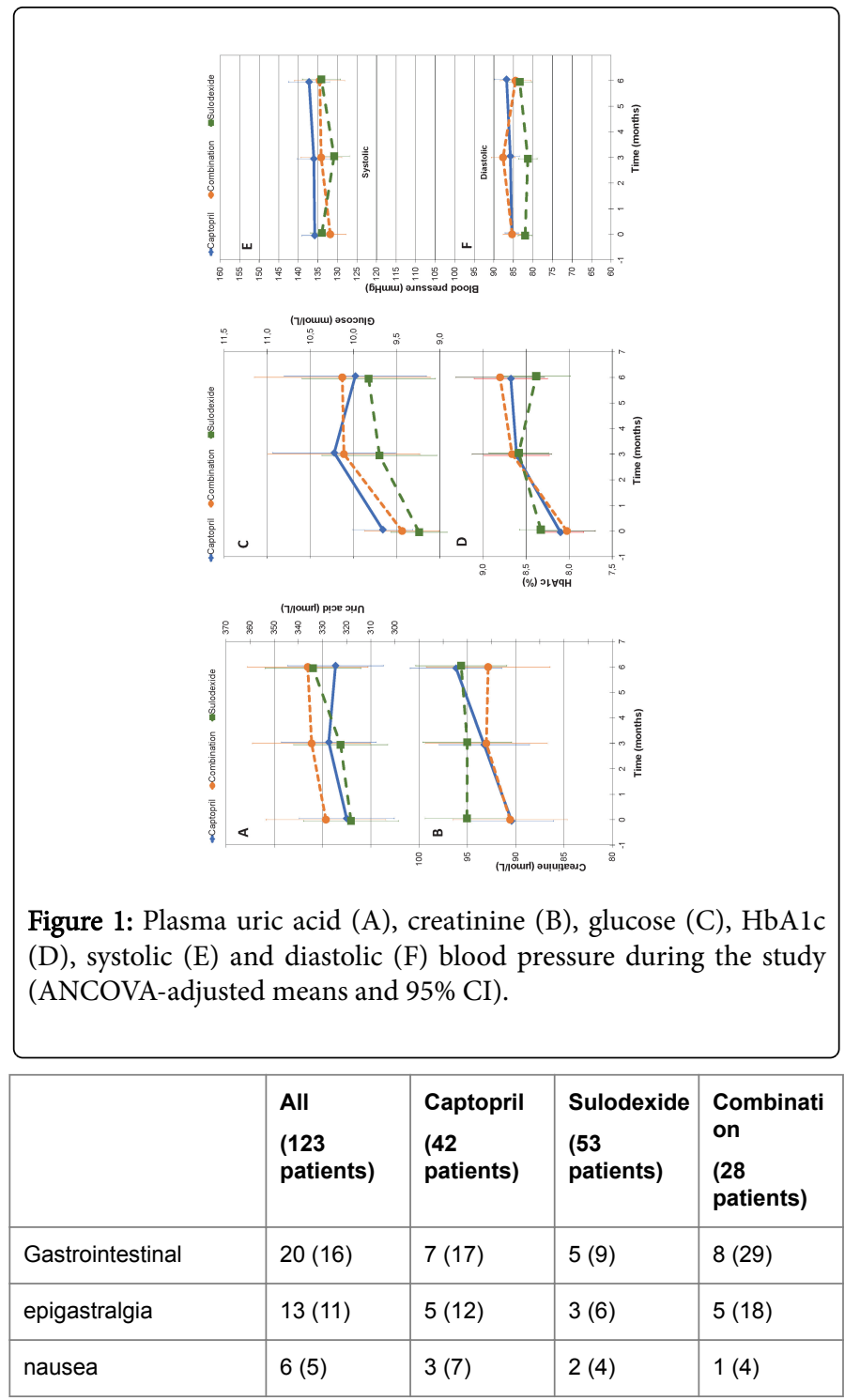




\begin{tabular}{|l|l|l|l|l|}
\hline vomiting & $2(2)$ & $0(0)$ & $1(2)$ & $1(4)$ \\
\hline diarrhea & $4(3)$ & $1(2)$ & $1(2)$ & $2(7)$ \\
\hline Other & $4(3)$ & $3(7)$ & $0(0)$ & $1(4)$ \\
\hline cough & $3(2)$ & $2(5)$ & $0(0)$ & $1(4)$ \\
\hline leukopenia & $1(1)$ & $1(2)$ & $0(0)$ & $0(0)$ \\
\hline Any adverse event & $23(19)$ & $9(21)$ & $5(9)$ & $9(32)$ \\
\hline
\end{tabular}

Table 5: Adverse events. Entries are N (\%).

\section{Discussion}

This study was undertaken to compare the efficacy and safety of sulodexide, alone or in combination with captopril, versus captopril alone administered for 6 months in diabetic patients with persistent albuminuria. Increased urinary albumin excretion is an early and important finding of diabetic nephropathy, occurring in about $20-40 \%$ of diabetic patients, and associated with an increased risk of developing end-stage renal disease, as well as significant cardiovascular morbidity [1-4]. Pharmacological intervention on the reninangiotensin-aldosterone system with ACE-I and ARBs has proven to be able to reduce albuminuria and protect the kidney, independently of their blood pressure reducing properties. Captopril, a well-known and used ACE-I, demonstrated to preserve the kidney function and to reduce proteinuria in diabetic nephropathy in several clinical trials and was chosen as comparator drug in this study [24-27]. Besides, Roozbeh et al. showed recently that combining captopril and another drug effective in improving diabetic nephropathy can lead to a greater reduction in proteinuria than captopril alone [28].

In our study, all the study drugs were able to significantly reduce proteinuria compared to baseline, but the reduction was higher in the groups treated with sulodexide $(31.7 \%$ and $31.2 \%$ at month 3 and $44.7 \%$ and $51.2 \%$ at month 6 respectively for sulodexide and sulodexide plus captopril) than in the group treated with captopril alone (16.5\% at month 3 and $31 \%$ at month 6$)$. After correction for multiplicity, the intergroup comparison was statistically significant in favour of the monotherapy with sulodexide at month 3 and in favour of the combination of sulodexide plus captopril at month 6 with respect to captopril alone. Another important finding of our study was that in all the study groups the reduction was higher in patients with microalbuminuria than in patients with macroalbuminuria, suggesting the need of a pharmacological intervention in an early stage of the renal disease.

Our results are in agreement with previous clinical experiences carried out both in type 1 and type 2 diabetes patients, which highlighted the potential role of sulodexide. A retrospective analysis of 12 clinical trials enrolling approximately 600 patients with diabetes showed that sulodexide has anti-albuminuric effects and lower AER in patients with diabetes and either microalbuminuria or macroalbuminuria. In most of these studies it was demonstrated that the effect of sulodexide on reducing albuminuria was sustained up to four months after cessation of treatment, strongly suggesting that a biochemical-anatomic remodelling is potentially initiated in renal tissue by sulodexide [17].

The most important study performed in type 1 and 2 diabetic nephropathy with micro- and macroalbuminuria was the Di.N.A.S. (Diabetic Nephropathy and Albuminuria Sulodexide) trial [18]. Two

hundred and twenty-three patients were randomly assigned to receive orally 50,100 or $200 \mathrm{mg}$ daily of sulodexide or matched placebo for 4 months, with a 4 month follow up period after drug suspension. At the end of the treatment, the reduction of AER was significantly different from placebo $(\mathrm{p}<0.05)$ and positively correlated with dose increments ( $30 \%$ for $50 \mathrm{mg} /$ day, $49 \%$ for $100 \mathrm{mg} /$ day and $74 \%$ for $200 \mathrm{mg} /$ day). Very interestingly, sulodexide was similarly effective in both type 1 and 2 diabetic patients, in both micro- and macroalbuminuric patients and in patients with or without concomitant ACE-I therapy, showing that these drugs and sulodexide do not interfere with each other and have different mechanisms of action [18].

However, the Di.N.A.S. trial clearly demonstrated not only that the hypoalbuminuric effect of sulodexide is dose-related, but also that it increases over time. On this basis, another study evaluated the effects of a long-term administration (12 months) of sulodexide at low dosage $(50 \mathrm{mg} /$ day) on albuminuria in diabetic patients [19]. At 6 and 12 months, albuminuria was greatly reduced in patients treated with sulodexide and increased in the control group $(-38.1 \% /-58.8 \%$ and $+19.1 \% /+29.4 \%$ vs. baseline, respectively; $\mathrm{p}=0.0001)$. The same figures were observed in both type 1 and type 2 diabetes and in both micro and macroalbuminuric patients. The hypoalbuminuric effect of 50 $\mathrm{mg} /$ day sulodexide further increased from 6 to 12 months and was greater than that observed in the Di.N.A.S. trial (the difference may be explained by the longer duration of drug administration before albuminuria evaluation) [19].

These studies show that even the lowest sulodexide dosage is effective provided the drug is administered for as long as 6 months: this was the rationale of the DAVET (Diabetic Albuminuria Vessel Tunisia) Study, by Blouza and colleagues [20]. The administration of 50 $\mathrm{mg} /$ day of sulodexide for 6 months to 269 diabetic patients was able to significantly and progressively reduce the AER $(\mathrm{p}<0.0001)$ : the geometric mean after 3 and 6 months was $63.7 \%$ (95\% CI, $59.3 \%-68.4 \%)$ and $42.7 \%$ (95\% CI, 37.8\%-48.2\%) of baseline, respectively, meaning a reduction of $36.3 \%$ and $57.3 \%$. The reduction was similar in type 1 and type 2 diabetes and was slightly greater in macroalbuminuric than in microalbuminuric patients [21].

The results of our study provide a further confirmation of the efficacy of 6 months treatment with a low dosage of sulodexide in diabetic patients with nephropathy, both in monotherapy and combined with an ACE-I.

The safety profile of sulodexide evaluated by Weiss in 12 clinical studies suggests that both intramuscular and oral administered dose of sulodexide ranging from $50 \mathrm{mg}$ to $400 \mathrm{mg}$ is well tolerated and safe [17]: in our experience, approximately $19 \%$ of the patients experienced one or more adverse events, mostly gastrointestinal, but the incidence was higher in patients treated with captopril alone $(21 \%)$ or with the combination $(32 \%)$ than in patients treated with sulodexide alone (9\%).

This study has some limitations. Firstly, treatment assignment was not randomised but was left to the choice of the investigators. Patients given the combination were mostly macroalbuminuric whereas patients given sulodexide were mostly microalbuminuric, with captopril in an intermediate condition. This difference reflects the physicians' need of new treatments for the management of the most severe patients, unresponsive to ACE-I alone. Although these differences are of interest in highlighting the criteria for treatment preference in clinical practice, they constitute a major limitation for the comparability of treatment effects in this study. The comparability issue 
was made more compelling by the finding that for each treatment microalbuminuric patients responded better than macroalbuminuric patients in terms of percent reduction of baseline AER. Therefore any comparison between treatments must be carried out either by stratification (separate tests within microalbuminuric patients and within macroalbuminuric patients) or by multivariate analysis adjusting for baseline AER imbalance. The latter was preferred to avoid further splitting into treatment strata of less than 10 patients (sulodexide in macroalbuminuria and combination in microalbuminuria). Furthermore, multivariate analysis allows adjustment for possible covariate imbalances other than baseline albuminuria. The results obtained with different treatments within the multivariate analysis were therefore not affected by differences in baseline albuminuria, DM type and DM duration, as far as statistical balancing permits. Even so, it should be recognised that statistical techniques are a surrogate, not a substitute, for randomisation of the treatments being compared. Therefore, the results of this study should be interpreted cautiously. To reduce the risk of spurious outcomes, however, alternative analyses were performed that supported the same conclusions of the main analyses presented in this paper. Also, as each treatment was compared with the other two, p-values have been corrected for multiple comparisons, i.e., setting to 0.05 the cumulative probability of a false-positive error (to declare a difference between treatments when there is none) in any of the pairwise comparisons on the same variable. A subgroup analysis according to type 1 and type 2 diabetes was not performed due to the very limited numbers of type 1 diabetic patients enrolled in each group.

Long term administration of sulodexide $50 \mathrm{mg} /$ day, both in monotherapy and in combination with captopril, was effective and well tolerated in reducing proteinuria in diabetic patients; the effect was greater in microalbuminuric patients. Together with previously mentioned studies, our results further support the role of sulodexide in diabetic nephropathy as valid partner of ACE-I/ARBs in difficult-totreat cases or as single agent in case of patients with contraindications to the use of these agents (poor tolerability or co-morbidities). Furthermore, sulodexide has other pharmacological effects potentially useful in the diabetic patients, subject to a high probability of developing acute cardiovascular diseases: anti-thrombotic activity, decrease of oxidative stress, hypolipidemic effect, prevention of glucose toxicity, suppression of cellular inflammation and anti-atheromatous effects [6]. Several clinical studies demonstrated sulodexide efficacy in patients, diabetic and not diabetic, affected by vascular diseases associated with a thrombotic risk: peripheral occlusive arterial diseases $[29,30]$, prevention of recurrent deep venous thrombosis [31,32], diabetic retinopathy [33], diabetic foot [34,35], cerebrovascular $[36,37]$ and cardiovascular diseases [38,39] and management of chronic venous disease, including the more severe and complicated cases such as venous ulcers [40-42].

In conclusion, due to its several pharmacological effects, sulodexide can be considered a valid therapeutical option in the management of diabetic patient, in order to prevent major complications and reduce morbidity and mortality in this population.

\section{Acknowledgement}

The authors thank Dr. G. Airoldi for the statistical analysis of efficacy data.

\section{References}

1. Coccheri S (2007) Approaches to prevention of cardiovascular complications and events in diabetes mellitus. Drugs 67: 997-1026.

2. Abaterusso C, Gambaro G (2006) The role of glycosaminoglycans and sulodexide in the treatment of diabetic nephropathy. Treat Endocrinol 5: 211-222.

3. Masola V, Zaza G, Gambaro G (2014) Sulodexide and glycosaminoglycans in the progression of renal disease. Nephrol Dial Transplant 29: i74-i79.

4. Van Buren PN, Toto R (2013) Current update in the management of diabetic nephropathy. Curr Diabetes Rev 9: 62-77.

5. de Zeeuw D1 (2007) Albuminuria: A target for treatment of type 2 diabetic nephropathy. Semin Nephrol 27: 172-181.

6. Gaddi AV, Cicero AF, Gambaro G (2010) Nephroprotective action of glycosaminoglycans: Why the pharmacological properties of sulodexide might be reconsidered. Int J Nephrol Renovasc Dis 3: 99-105.

7. Ravera M, Re M, Weiss U, Deferrari L, Deferrari G (2007) Emerging therapeutic strategies in diabetic nephropathy. J Nephrol 20 Suppl 12: S23-32.

8. Hoppensteadt DA, Fareed J (2014) Pharmacological profile of sulodexide. Int Angiol 33: 229-235.

9. Lauver DA, Lucchesi BR (2006) Sulodexide: A renewed interest in this glycosaminoglycan. Cardiovascular Drug Reviews 24: 214-226.

10. Milani M, Barbanti M, Calanni F, Marchi E (1990) Anticoagulant and fibrinolytic pharmacokinetics of sulodexlde in man. Fibrinolysis 4: 99.

11. Cristofori M, Mastacchi R, Barbanti M, Sarret M (1985) Pharmacokinetics and distribution of a fluoresceinated glycosaminoglycan, sulodexide, in rats. Part I: Pharmacokinetics in rats. Arzneimittelforschung 35: 1513-1516.

12. Klausen K, Borch-Johnsen K, Feldt-Rasmussen B, Jensen G, Clausen P, et al. (2004) Very low levels of microalbuminuria are associated with increased risk of coronary heart disease and death independently of renal function, hypertension, and diabetes. Circulation 110: 32-35.

13. Solini A, Carraro A, Barzon I, Crepali G (1994) Therapy with glycosaminoglycans lowers albumin excretion rate in non-insulin dependent diabetic patients with macroalbuminuri. Diabetes Nutrition and Metabolism 7: 304-307.

14. Gambaro G, Cavazzana AO, Luzi P, Piccoli A, Borsatti A, et al. (1992) Glycosaminoglycans prevent morphological renal alterations and albuminuria in diabetic rats. Kidney Int 42: 285-291.

15. Rossini M, Naito T, Yang H, Freeman M, Donnert E, et al. (2010) Sulodexide ameliorates early but not late kidney disease in models of radiation nephropathy and diabetic nephropathy. Nephrol Dial Transplant 25: 1803-1810.

16. Weiss R, Niecestro R, Raz I (2007) The role of sulodexide in the treatment of diabetic nephropathy. Drugs 67: 2681-2696.

17. Weiss R, Niecestro E, Raz I (2007) Efficacy and safety of sulodexide in the treatment of diabetic nephropathy. 67th Scientific Session ADA.

18. Gambaro G, Kinalska I, Oksa A, Pontuch P, Hertlová M, et al. (2002) Oral sulodexide reduces albuminuria in microalbuminuric and macroalbuminuric type 1 and type 2 diabetic patients: the Di.N.A.S. randomized trial. J Am Soc Nephrol 13: 1615-1625.

19. Achour A, Kacem M, Dibej K, Skhiri H, Bouraoui S, et al. (2005) One year course of oral sulodexide in the management of diabetic nephropathy. J Nephrol 18: 568-574.

20. Heerspink HL, Greene T, Lewis JB, Raz I, Rohde RD, et al. (2008) Effects of sulodexide in patients with type 2 diabetes and persistent albuminuria. Nephrol Dial Transplant 23: 1946-1954.

21. Blouza S, Dakhli S, Abid H, Aissaoui M, Ardhaoui I, et al. (2010) Efficacy of low-dose oral sulodexide in the management of diabetic nephropathy. J Nephrol 23: 415-424.

22. Everitt BS (1995) The analysis of repeated measures: A practical review with examples. The Statistician 44: 113. 
Citation: Dakhli S, Khedher A, Borni Z, Achour A, Hachicha J (2016) A Clinical Experience on Sulodexide in the Treatment of Patients with Diabetic Nephropathy. J Nephrol Ther 7: 284. doi:10.4172/2161-0959.1000284

Page 9 of 9

23. SAS Institute Inc (2009) SAS/STAT Software 9.2 User's Guide (2nd edn.) SAS Institute INC, Cary, NC.

24. Laffel LM, McGill JB, Gans DJ (1995) The beneficial effect of angiotensinconverting enzyme inhibition with captopril on diabetic nephropathy in normotensive IDDM patients with microalbuminuria. North American Microalbuminuria Study Group. Am J Med 99: 497-504.

25. No authors listed (1996) Captopril reduces the risk of nephropathy in IDDM patients with microalbuminuria. The Microalbuminuria Captopril Study Group. Diabetologia 39: 587-593.

26. Mathiesen ER, Hommel E, Hansen HP, Smidt UM, Parving HH (1999) Randomised controlled trial of long term efficacy of captopril on preservation of kidney function in normotensive patients with insulin dependent diabetes and microalbuminuria. BMJ 319: 24-25.

27. Vörös $P$, Lengyel Z, Németh C, Mirzahosseini S, Kammerer L, et al (1998) The efficacy of long-term captopril treatment on micro- and macroalbuminuria in hypertensive diabetics. Geriatr Nephrol Urol 8: 65-68.

28. Roozbeh J, Banihashemi MA, Ghezlou M, Afshariani R, Salari S, et al. (2010) Captopril and combination therapy of captopril and pentoxifylline in reducing proteinuria in diabetic nephropathy. Ren Fail 32: 172-178.

29. Gaddi A, Galetti C, Illuminati B, Nascetti S (1996) Meta-analysis of some results of clinical trials on sulodexide therapy in peripheral occlusive arterial disease. J Int Med Res 24: 389-406.

30. Coccheri S, Scondotto G, Agnelli G, Palazzini E, Zamboni V, et al. (2002) Sulodexide in the treatment of intermittent claudication. Results of a randomized, double-blind, multicentre, placebo-controlled study. Eur Heart J 23: 1057-1065.

31. Cirujeda JL, Granado PC (2006) A study on the safety, efficacy, and efficiency of sulodexide compared with acenocoumarol in secondary prophylaxis in patients with deep venous thrombosis. Angiology 57: 53-64.

32. Andreozzi GM, Bignamini AA, Davì G, Palareti G, Matuška J, et al. (2015) Sulodexide for the prevention of recurrent venous thromboembolism: The sulodexide in secondary prevention of recurrent deep vein thrombosis (SURVET) study: A multicenter, randomized, double-blind, placebo-controlled trial. Circulation 132: 1891-1897.
33. Song JH, Chin HS, Kwon OW, Lim SJ, Kim HK, et al. (2015) Effect of sulodexide in patients with non-proliferative diabetic retinopathy: Diabetic retinopathy sulodexide study (DRESS). Graefes Arch Clin Exp Ophthalmol 253: 829-837.

34. Koblik T, Sieradzki J, Sendur R, Biernat J, Czarnobilski K, et al. (2001) The effect of insulin and sulodexide (Vessel Due F) on diabetic foot syndrome: pilot study in elderly patients. J Diabetes Complications 15: 69-74.

35. Svetukhin AM, Zemlianoi AB, Orudzheva SA, Titova MI, Rudneva VG, et al. (2001) Experience in the use of vessel due F (sulodexide) in patients with suppurative-necrotic forms of diabetic foot without critical ischemia. Ter Arkh 73: 31-33.

36. Parnetti L, Mari D, Abate G, Balestreri R, Cucinotta D, et al. (1997) Vascular dementia Italian sulodexide study (VA.D.I.S.S.). Clinical and biological results. Thromb Res 87: 225-233.

37. Abate G, Pennese F, Altiglla F, Buonaiuto S, Caione F, et al. (1991) II Sulodexide in cerebrovascular disease of 'elder. Minerva Angiologica 16: 137-139.

38. Tramarin R, Febo O, Cobelli F, Colombo E, Opasich C, et al. (1987) Effect of low molecular weight Heparin A (Sulodexide) thrombosis in left ventricular post-infarction: Echocardiographic study. Med Praxis 8: 1-11.

39. Condorelli M, Chiariello M, Dagianti A, Penco M, Dalla Volta $S$, et al. (1994) IPO-V2: A prospective, multicenter, randomized, comparative clinical investigation of the effects of sulodexide in preventing cardiovascular accidents in the first year after acute myocardial infarction. J Am Coll Cardiol 23: 27-34.

40. Saviano M, Maleti O, Liguori L (1993) Double-blind, double-dummy, randomized, multi-centre clinical assessment of the efficacy, tolerability and dose-effect relationship of sulodexide in chronic venous insufficiency. Curr Med Res Opin 13: 96-108.

41. Scondotto G, Aloisi D, Ferrari P, Martini L (1999) Treatment of venous leg ulcers with sulodexide. Angiology 50: 883-889.

42. Coccheri S, Scondotto G, Agnelli G, Aloisi D, Palazzini E, et al. (2002) Randomised, double blind, multicentre, placebo controlled study of sulodexide in the treatment of venous leg ulcers. Thromb Haemost 87: 947-952. 